3051 words

4 Tables

2 Figures

33 refs

\title{
A Comparison of Neuropsychiatric and Cognitive Profiles in Delinium, Dementia, Comorbid Delinium-Dementia, and Cognitively Intact Controls
}

\author{
David J . Meagher1,2 \\ Maeve Leonard 1 \\ Sinead Donnelly 3 \\ Marion Conroy 3 \\ J ean Saunders4 \\ Paula T. Trzepa c z5-8
}

1Department of Adult Psychiatry, Midwestem Regional Hospital, Limerick, Ireland and University of Limerick Medical Sc hool, Limerick, Irela nd 2 Health Systems Research Centre, University of Limerick, Ireland.

3 Milford Hospice Pallia tive Care Centre, Limerick, Ireland

4 Sta tistic al Consulting Unit, University of Limerick, Irela nd

5 Lilly Research Laboratories, India napolis, Indiana, USA

6University of Mississippi Medic al Sc hool, USA

Tufts University Sc hool of Medic ine, USA

IIndiana University School of Medicine, USA

Correspondence to Professor David Meagher, University of Limerick Medica I School, Ireland (david.meagher@ul.ie) (00353-61-315177)

Key Words : Delinum, dementia, phenomenology, assessment, diagnosis 


\section{ABSTRACT}

Purpose: Delirium and dementia have overlapping features that complic ate differential dia gnosis. Delirium symptoms overshadow dementia symptoms when they co-occur, but delinum phenomenology in comorbid cases has not been compared to both conditions alone.

Methods: Consec utive a dults with DSM-IV delinum, dementia, comorbid delinumdementia, and cognitively intact controls were assessed using the Revised Delinum Rating Scale (DRS-R98) and Cognitive Test for Delinum (CTD).

Results : Delinum and comorbid delinum-dementia groups had comparable DRSR98 and CTD total scores which were greater than in dementia or control groups. On the DRS-R98, multiple non-cognitive symptoms, inattention and disorientation were more severe in delinum groups compared with dementia-alone. Patients with dementia differed from both delinum groups on the CTD test of attention. Spatial span backwards was signific antly lower in all patients with cognitive impaiment (delinum, comorbid delinum-dementia, dementia alone) compared to controls, whereas spatial span forwa rds distinguished delinum groups from dementia.

Conclusions: Delinum phenomenology is similar with or without comorbid dementia. A wide range of neuropsychia tric symptoms distinguish delinum from dementia. Spatial span forward is disproportionately diminished in delirium , suggesting usefulness as a differentiating sc reening test. 
Declaration of interest The authors wish to acknowled ge the support and cooperation of nursing and medical staff at Milford Hospice Pallia tive care centre. This study was sup ported through departmental funds at Limerick Mental Health services. Unrelated to this research, Dr. Meagher has received research grant funding from Astra-Zeneca and has acted as a advisory consultant for Pfizer, EliLilly, Bristol-Meyers, and J anssen Pha ma ceutic a ls as well as receiving travel support from Smith-Kline Beecham, Eli-illy, Astra-Zeneca, Nova rtis, Wyeth, and Bristol-Meyers Pha ma ceutic als Ltd. Dr. Trzepacz is a full-time sa la ried employee of Eli Lilly and Company and shareholder of Lilly. Lilly does not have a product with an indic ation for delinum. Dr. Trzepacz owns the copyright for the Delinum Rating Scale- Revised-98 but does not charge a fee for its use except in for-profit situations.

Competing Interest None declared.

\section{Licence for Publication:}

The Corresponding Author has the right to grant on behalf of all authors and does grant on beha If of all authors, an exclusive licence (or non exclusive for govemment employees) on a world wide basis to the BMJ Publishing Group Ltd to permit this a rticle (if accepted) to be published in J NNP and any other BMJ PG L products and sublicences such use and exploit all subsidiary rights, as set out in the licence. (http://group.bmj.com/products/jouma ls/ instructions-forauthors/lic ence-forms) 


\section{Introduction}

Delinum and dementia are the two major generalised cognitive disorders that historic ally have been distinguished by features such as temporal course and reversibility, with delinum considered more acute in onset and fluctuating in daily symptom severity while dementias associated with a deteriorating course. The cardinal cognitive disturbance in delinum is inattention while in most dementias there is disproportionate memory disturbance with relatively preserved attention. Distinction of these disorders is important because the urgency of investigation and treatment is greater for delinum which can reflect a medical emergency. However, some dementias have a more acute onset (e.g. dementia of Lewy body type, large CVA-related dementia) and distinction is further complic ated by the high comorbidity such that dementia co-occurs in as many as two third sof delinum cases in elderly popula tions (1). Moreover, persistent cognitive impaiments have been described during longer term follow up of eldenly patients experiencing delinum, raising questions a bout reversibility and prognosis after a delinum episode (2).

While acute onset, fluctuating course, and attribution to an id entifiable temporally rela ted etiology a re useful distinguishing features for delinum diagnosis, there are surprisingly few studies that have compared delinum phenomenology between delinum and dementia. Most compared delinum symptoms between delinum and comorbid delinum-dementia groups, but without a 'pure' dementia group (3-7). Moreover, there has been limited study companing cognitive profiles in these 
disorders. Floor effects for neuropsychologic al tests also make it challenging to find instruments useful in delinum where the level of cognitive impa iment is quite severe. Two specific and validated tools have allowed formore detailed study of delinum: the Cognitive Test for Delinum [CTD](8) that mea sures five cognitive domains using standard neuropsychological methods and the Delinum Rating Scale-Revised-98 [DRS-R98](9) that measures a broad range of delinum symptoms not measured by other delinum instruments including language, thought process, visuospatial ability, and both short and long-term memory.

We report a study in a palliative care setting compa ring the severity of delinum symptoms in nondemented control patients to those with delinum, dementia, and comorbid delinum-dementia using the DRS-R98 and the CTD. In partic ularwe a imed to address: (1) How does neuropsychiatric and cognitive profile in comorbid delirium-dementia compare to that of either disorder alone when analysed in conjunction with controls in the same setting and (2) Which features best differentia te controls from delinum or dementia, a nd delinum groups from dementia.

\section{METHODS}

\section{Subjects and Design}

We conducted a prospective cross-sectional study of delinum symptoms and cognitive performance in consec utive a dult cases of delinum, dementia, comorbid delinum-dementia, and cognitively normal compa rison subjects 
receiving care in the same palliative care inpatient service. Cases with altered mental state were identified on daily rounds by the palliative care medical team and consecutively referred for delinum diagnosis according to DSM IV criteria by the research team. Assessments were conducted by trained raters in the use of the DRS-R98 and CTD (ML or DM) and to further enhance interra ter reliability, difficult ratings were discussed and rated by consensus between both raters. Patients who had nomal cognition as detemined by an Abbreviated Mental Test (10) score greater than 6 points and no prior history of cognitive disturbance were randomly rec ruited for assessment. Dementia was defined as the presence of persistent cognitive impa iment for at lea st 6 months prior to the assessment and perDSM criteria based on all available information at the time of assessment including clinic al ca se notes and collateral history from fa mily and / or carers (11). Comorbid delinum-dementia was defined as the presence of both disorders. Each case was then assessed by first completing the DRS-R98 followed by administration of the CTD. The DRS-R98 rated the preceding 24 hour period whereas the CTD measured cognition at the time of its a dministration. CTD responses were not used to rate DRS-R98 items. Both the DRS-R98 and the CTD are well valid ated instruments, highly structured and anchored for rating and scoring.

\section{Informed Consent}

The procedures and rationale for the study were explained to all patients but because many patients had cognitive impaiment at entry into the study it was presumed that most were not capable of giving informed written consent. Because of the non-invasive nature of the study ethics committee approval was 
given to augment patient a ssent with proxy consent from next of kin (where possible) or a responsible caregiver for all participants in accordance with the Helsinki Guidelines for Medical research involving human subjects (12).

\section{Assessments}

Demographic data, medical diagnoses, and medication at the time of the assessment were recorded. All available information from medical records and where possible collateral history was used. Nursing staff were interviewed to assist rating of symptoms over the previous 24 hours.

The Delinum Rating Scale-Revised-98 [DRS-R98](9) is designed for broad phenomenologic al assessment of delinum. It is a 16 -item scale with 13 severity and 3 diagnostic items with high interra ter relia bility, sensitivity and specific ity for detecting delinum in mixed neuropsychiatric and other hospital populations (9). Each item is rated 0 (absent/nomal) to 3 (severe impaiment) with descriptions anchoring each severity level. Severity scale scores range from 0-39 with higher scores indic ating more severe delinum. Delinum typic a lly involves scores a bove 15 points (Severity scale) or 18 points (Total scale) when dementia is in the differential diagnosis. For determination of item frequencies in this study, any item score $\geq 1$ was considered as being "present". DRS-R98 items can be divided into cognitive (\#9-13) and non-cognitive (\#1-8) subsca les based on construct validity.

The Cognitive Test for Delinum [CTD](8) was specific a lly designed to assess hospitalized delinum patients, in particular those who are intubated or una ble to 
speak or write. It assesses five neuropsychological doma ins (orienta tion, attention, memory, comprehension, and vigilance) emphasizing nonverbal (visual and auditory) modalities. Tests are components of standardized and widely used neuropsychologic al tests. Attention on the CTD is assessed visually using the spatial span test (forwards and backwards) from the Wechsler Memory Scale (13). Each individual doma in is scored from $0-6$ by 2 point inc rements, except for comprehension (single point increments). Total scores range between 0-30 with higher sc ores indic ating better cognitive function and scores of less than 19 consistent with delinum. It reliably differentiates delinum from other neuropsychia tric conditions including dementia, schizophrenia and depression (13).

\section{Statistic al Analyses}

Statistic al analysis was conducted using the SPSS-14.0 package. Demographic and rating scale data were expressed as means plus standard deviation. Continuous variables (e.g. age, total DRS-R98 and CTD scores) were compared by one way ANOVA with independent t-tests used for post hoc companisons. _Non-nomal data (e.g. DRS-R98 and CTD item scores) were compared with Mann-Whitney U tests for between group comparisons with a Bonferroni correction level of $p \varangle 0.005$ a pplied for the DRS-R98 item companisons. Correlations between DRS-R98 and CTD item scores were made using Speaman's rank correlation coeffic ient. 


\section{RESULTS}

Demographic and medication data forpatients from the fourgroups are shown in

Table 1. Both groups with evidence of dementia were signific a ntly older $(p \varangle 0.001)$ than the delinum and cognitively intact control groups. The principal causes of delinum ( $n=80$ ) were systemic infection (29), meta bolic disturbance (26), drug intoxic ation (17) while 11 subjects from the delirium groups had a documented CNS neoplastic lesion. The dementia had been diagnosed in 10 cases (3 with Alzheimer's dementia, 2 with vascular dementia, 5 with unspecified type) and was newly documented in a further 10 cases. Two patients from the dementia group had a documented CNS neoplastic lesion. The overall number of medications used was similar for the four groups but when a nalysis was restric ted to psychotropic agents, the delinum groups both had more than the other groups. This principally reflected greater use of a ntipsychotic agents in delinum (67\%) and delinum-dementia (58\%) groups vs. dementia (22\%) and controls $(30 \%)(p=0.002)$.

Table 2 compares mean scores for delinum groups vs dementia and control groups for the DRS-R98 total and severity sca les, DRS-R98 cognitive and non-cognitive subsc ales, and tota I CTD. Controls were signific antly less impaired on all scores tha $n$ any other group, scoring in normal ranges $(P \varangle 0.001)$. Comorbid delinumdementia was not signific a ntly different from delinium except that the noncognitive subsc ale was higher in delinum $(p=0.04)$. Comorbid delinum-dementia differed from dementia on all DRS-R98 and CTD scores. Total C TD score showed only a trend $(p=0.07)$ for delinum vs dementia. Only 2 in the dementia group (10\%) had DRS-R98 total scores above 15 while 6 had totaI CTD scores less than 19. Figure 
1 compares median total DRS-R98 scores for the 4 groups. Scores were higher for both delinum groups compared with dementia $(p<0.001)$ and greater for dementia compared with controls $(p<0.001)$. Scores did not differ between delinum groups.

Mean scores for DRS-R98 items are described in Table 3. Only language was similar across all groups. Both delinum and delinum-dementia groups had higher scores for the majonity of symptoms when compared with dementia alone and were comparable to each other except for thought process abnomality that was worse in delinum than delinum-dementia. A wide range of DRS-R98 noncognitive items (sleep-wake cycle, perceptual abnomality, affective lability, thought process abnomality, motor agitation and motor retardation) were more severe in both delinum groups as compared to dementia, but only thought process abnomalities and motor a gitation rema ined statistic ally signific a nt a fter correction for multiple testing. The only cognitive items that distinguished these groups were attention and orientation but in both cases this did not reach statistic al signific a nce after correction for multiple testing. Delinum dia gnostic items (symptom fluctuation, ac ute onset, and attributable physic al disorder) signific a ntly distinguished delinum groups from the other groups but did not distinguish dementia from controls. The dementia group differed from the control group only on the five cognitive symptoms.

Table 4 shows the comparison of individual CTD item scores between the four groups. Controls performed in the nomal range and were significantly less 
impaired than any other group on each item $(p \varangle 0.001)$ except orientation. No item distinguished comorbid delinum-dementia from delinum and only attention distinguished delinum-dementia from dementia $(p \varangle 0.05)$. However, both attention and vigilance distinguished delinum from dementia $(p<0.05)$. Dementia differed from controls on all 5 items of the CTD at $p \varangle 0.001$.

Closer examination of the components of the CTD attention item - spatial span forward (SSF) and backward (SSB) measured in a visual modality - revealed that mean SSF in controls (5.7 \pm 1.6$)$, dementia $(4.1 \pm 2.1)$, delinum $(2.6 \pm 1.9)$ and delinum dementia $(2.8 \pm 2.3)$ was signific antly worse for delinum vs. dementia $(p=0.02)$ and for comorbid deliirum-dementia vs dementia $(p=0.05)$ but did not differ between delinum groups. Mean SSB did not distinguish the three cognitively impaired groups from each other (dementia $=2.1 \pm 1.7$; delinum $=1.3 \pm 1.6$; and delinum-dementia $1.3 \pm 1.7$ ) but rea dily distinguished all three groups from controls (mean $4.0 \pm 1.5$ ) at $p<0.001$. Nomal performance on SSF is $7 \pm 2$ and on SSB is typically $5+2$ points (14). Additionally, median scores differed significantly in a similar fashion, where distributions (see figure 2) of the middle two quartiles overlapped only partially for dementia and the comorbid group for SSF whereas there was no overlap for SSB a cross the three cognitively impaired groups.

Only one person (2.5\%) in the cognitively intact control group and $3(15 \%)$ in the dementia group scored less than four points on the spatial span forwards, while 26 (65\%) of the delinum group and 25 (62\%) of the comorbid delinum-dementia group scored three or less. Using a cutoff score of less than 4 on the SSF to indicate 
delinum, within the three cognitively impaired groups Positive Predic tive Value was 95\% and Negative Predic tive Value 35\%. This suggests that subjects that sc ore 3 or less on the SSF c amy a high likelihood of having delinum (95\%) but that higher scores are less useful for outruling the presence of delinum.

The relationship between perceptual disturbances / halluc inations, visuospatial function and inattention in the cognitively impaired groups was compared with correlational a nalysis of DRS-R98 item 2 (perceptual disturbances and halluc inations), item 10 (inattention) and item 13 (visuospatial function) as well as the SSF and SSB scores from the CTD. This indic ated no signific ant relationship between perceptual disturbances and any of the mea sures of visuospatial function or attention in any of the cognitive groups ( $r_{s}$ all $<0.15$ ). In contrast, scores for visuospatial function correlated signific antly with SSF $\left(r_{s}=0.53 ; p<0.001\right)$ and SSB $\left(r_{s}=0.46 ; p \varangle 0.001\right)$ for the delinum groups but not for the dementia-only group.

\section{DISCUSSION}

In contrast to previous studies, we compared delinum phenomenology in comorbid delinium-dementia to that of both delinum and dementia groups, with a control group in the same medical setting $(3-7,15)$. Further, our study used two well-validated instruments for d elirium symptom severity - the DRS-R98 a nd CTD which a llow for more detailed investigation of cognitive and neuropsychia tric profile in this complexsyndrome. 
The need to distinguish delinum and dementia is emphasized by the greater urgency of diagnosis for delinum which can be the first indic ation of serious medic al morbidity (16), and where late or non-detection is associated with markedly poorer outc omes includ ing elevated mortality rates (17). Treatment response to antipsychotic s is superior to use in dementia (18) where use for dementia agitation and psychosis is associated with increased mortality (19). These concems highlight the need to ca refully evaluate features, including phenomenological profile, in order to better distinguish these disorders (20) with revised diagnostic criteria in DSM-V and ICD-11 more accurately reflecting those differences. Further, comorbid delinum and dementia is understudied regarding its phenomenology and other implications, though evidence to date suggests that it is more similar to delinum. Some reports of persistent cognitive impa iment in eld enly delinious patients may reflect progression of previously undiagnosed dementia with poorer longer term prognosis than in uncomplic ated delinum episodes. This notion is supported by a range of neuropsyc hological studies (21) and is consistent with longitud inal work showing an inc rea sed delinum risk in patients who have executive cognitive impaiment upon admission, which reflects prehospitalization ba seline cognitive status (22).

Our data using both the DRS-R98 and CTD confimed that the domain of attentional defic its is the key distinguishing element of delinum as is represented in ICD (23) and DSM (11) diagnostic criteria where it is the cardinal and required symptom. We also found signific a ntly higher sc ores in delinum groups on DRS-R98 items for a cute onset, fluc tuating course and attribution to a physic al disorder. 
These features are well-represented in diagnostic criteria for delinium in DSM-IV and ICD-10. Further, we found evidence that supports the recently proposed 3 core doma ins of delinum - inattention (accompanied by other cognitive deficits), circadian activity disnuption (sleep-wake cycle disturbance and motor ac tivity a ltera tions), and impaired higher level thinking ability (24) - being specific to delinum because items were more impaired in both delinum groupsas compared to dementia. These core domain phenomenological features may be useful clinic ally in distinguishing delinum from dementia and should be considered for inclusion in revised ICD and DSM diagnostic criteria descriptions because current editions provide little or no guidance as to distinguishing features between delinum and dementia other than temporal course.

This study a lso supports previous work that comorbid delinum-dementia is virtua lly ind istinguishable from delinum alone but that it can be distinguished from dementia on a number of features, especially noncognitive ones. Altered motor ac tivity, a ffec tive la bility, and thought process a bnoma lities emerged as particula rly useful in distinguishing both delinum groups from dementia while severity of thought process abnomalities was the only item whic $h$ also distinguished delinum from comorbid delinum-dementia. These findings are largely consistent with those of Trzepacz and colleagues (25) where DRS-R98 items for sleep-wake cycle disturbance, thought process abnomality, motor a gita tion, perceptual disturbances, affective lability, attention, visuospatial a bility, a cute onset of symptoms, fluc tuation of symptoms and physic al disorder were signific a ntly worse in delinum vs. dementia, though their sa mples were 
smaller. Ourfindings contrast with the work of Cole et al (15) regarding thought process and motor a gitation levels in dementia vs. delinum, but they used instruments that detect only the presence or absence of delinium symptoms and not severity as the DRS-R98 does. Further, their work found no impaiment of consc io usness in hyperalert delinum subgroups but did in the hypoalert, which is disconcerting because delinum is by definition a disorder of impa ired consciousness. This also begs the question of what symptoms constitute impaired consciousness (sometimescalled "clouding") and how it is defined because this is an essential difference between delirium and dementia.

The CTD attention item, consistent with the DRS-R98 find ings, best differentiates delinum groups from control and dementia groups. Further, the SSF component of this item differentiated dementia from delinum groups whereas the SSB did not. SSF is a more specific test of simple attention involving primarily sequential processing while SSB requires greater processing of information, working memory, planning ability and sequential processing (26-28) with higher demands for exceptional levels of attention and concentration (29). Our data (e.g. positive predic tive value of $95 \%$ for a score of less than 4) suggest that SSF may be a useful bed side test that is rela tively simple and specific to help distinguish delinum from dementia but that it is less suited to outruling delinium due to a relatively high false negative rate. Confirmatory work is needed.

Brown and coworkers (30) identified signific antly poorer performance in patients with delinum versus Alzheimer's dementia on a range of tests of visual perception 
while delinious patients perfo med better on tests of memory. This work ra ises the question as to the extent to which defic its in these tests are related to impa iments of visual processing (e.g. in the occipital cortex) or attentional systems that direct processing towards visual inputs. Some work (31) has indic ated a correlation between perceptual a bnoma lities / hallucinations and impa iment of visual perception and attention in patients with dementia but the rela tionship between perceptual disturbances, visuospatial function and visual attention in different cognitive disorders rema ins unclear. Previous work using the Clock Drawing Test has indic ated that it is useful for identifying patients with cognitive impaiment but lacks specific ity for delinum vs dementia (32). Our work suggests that differences between delinum and dementia are more evident in tests of visual attention than tests of visuospa tial function. Moreover, we did not identify a major relationship between perceptual abnoma lities/hallucinations and either visual attention or visuospatial performance. Further work involving patients with different dementia types a re needed.

Noncognitive delinum symptoms failed to distinguish dementia patients from medic ally ill controls suggesting that the presence of noncognitive symptoms should alert clinicians to the possibility of delinum. Because we did not measure noncognitive symptoms with a dementia-specific scale like the Neuropsychiatric Inventory (33) that captures characteristic details of dementia phenomenology, we cannot be certain to what extent this would hold true for demented patients who are not hospitalized because neuropsychiatric symptoms are also common in dementia (34). However there are particular characteristics of noncognitive 
delinum symptoms that distinguish delinum from dementia patients such as type of sleep-wake cycle and perceptual disturbances, extreme and rapid nature of affective lability and degree of thought process abnomality that are captured differently on the DRS-R98 than on the NPI. Additionally, we did not evaluate the stage or type of dementia which could affect the presentation of noncognitive symptoms. While future work should evaluate dementia more carefully to tease part these more subtle features for differential diagnosis, it rema ins that delinum symptoms overshadow dementia when comorbid and that delinum, not dementia, is the medical prionity not to be missed.

Unfortunately, differentia ting symptoms other than inattention and temporal course are not emphasized in DSM-IV and ICD-10 delinum definitions, whereas disorganised thinking and sleep-wake cycle disturbance were emphasized in the DSM-III-R. Ourdata support their reinclusion in DSM-V. Provid ing better guidance regarding the distinction of delinum from dementia - and dementia from delinum - is a key challenge for future definitions of delinum in DSM-V (20) and ICD-11 (35).

\section{STUDY LMTATIONS}

Cross-sectional studies cannot fully capture the phenomenological profile of conditions such as delinum whose symptom severity fluctuates, though the DRSR98 utilizes a 24-hour reporting period. In keeping with the routine assessments conducted on all admissions to the unit, the cognitively intact group were id entified according to scores on the abbreviated mental test rather than a more 
standard test such as the MMSE (36) which would more accurately outrule the presence of cognitive impa iment typical of delinum and / or dementia. Dementia was diagnosed according to the presence of prior cognitive impaiment of at least six months duration. As such, a more accurate diagnosis might be obtained by using more specific criteria or an instrument such as the IQ CODE (37). We could not specify the primary cause of dementia (i.e. whether dementia was due to a degenerative process, vascular lesions, frontal dementia, alcohol, brain metastases, etc). There were fewer patients included in the dementia group perhaps reflecting the restrictions of our criteria, but also a function of the study setting where dementia is not as prevalent as in elderly medic ine settings. Pa tients in the two groups with dementia were signific antly older which might have impacted upon the performance in cognitive tests in particular but it is relevant that the principal finding in relation to cognition indicated a superior performance in the older patients with dementia-alone as well as significant differences with both the delinum-alone group and the comorbid delinum-dementia group which are not likely to relate to any age-associated effects. In addition, the different pattems of medic ation use, partic ularly in relation to antipsychotic agents, may have impacted ourfindings and warrant more deta iled analysis in future work. We used only delinum instruments to compare groups and future work should also include use of the NPI (33) which measures dementia neuropsychiatric phenomenology. However, ma ny of the NPI items are not descriptive of delinum and the ADAS-Cog (38) has not been reported in delinum heretofore and may have floor effects. The degree to which observations in a palliative care service (where patients have terminal illness and are often in receipt of polypha macy) 
can be generalised to patients in other settings is unc erta in. However, our data were remarkably similar to those of Trzepacz and colleagues (24) from other medical settings. Future work in other populations where delinum and va rious types of dementia are common, incorporating tools designed to assess neuropsychia tric profile in dementia, can address these shortc omings and further improve our understanding of the interface between these important and highly prevalent conditions. 


\section{REFERENCES}

(1) Fick DM, Agostini JV, Inouye SK. Delinum superimposed on dementia: a systematic review. J Am Geriatr Soc 2000; 50:1723-32.

(2) Trzepacz PT, MeagherDJ. Neuropsychia tric aspects of delinum. Chapter 11 in the American Psychiatric Publishing Textbook of Neuropsychiatry and Behavioral Neurosc iences (5 ${ }^{\text {th }}$ Edition). Eds Yud ofsky SC, Hales RE, American Psychia tric Publishing Inc, Wa shington DC, 2008, pp 445-517

(3) Liptzin B, Levkoff SE, G ottlieb GL, J ohnson JC. Delinum: background papers for DSM-IV. J Neuropsychiatry Clin Neurosci 1993; 5:154-160.

(4) Trzepa cz PT, Mulsant BH, Dew MA, et al (1998). Is delinum different when it occurs in dementia? A study using the Delinum Rating Scale. J Neuropsychiatry Clin Neurosci 1998; 10:199-204.

(5) La urila JV, Pitkala KH, Strandberg TE, Tilvis RS. Delinum among patients with and without dementia: does the diagnosis according to the DSM-IV differ from the previous classifications? International Journal of Geriatric Psychiatry 2004; 19:271-277.

(6) Voyer P, Cole MG, McCusker J, Belzile E. Prevalence and symptoms of delinum superimposed on dementia. Clinical Nursing Research 2006; 15:46-66. 
(7) Edlund A, Lundstrom M, Sandberg O, Bucht G, Brannstrom B, Gustafson Y. Symptom profile of delinum in older people with and without dementia. $J$ Geriatr Psych Neurol 2007; 20: 166-171.

(8) Hart RP, Levenson J L, Sessler CN, Best AM, Scwartz SM, Rutherford LE. Validation of a cognitive test for delinum in medic al ICU patients. Psychosomatics 1996; 37:533-46.

(9) Trzepacz PT, Mittal D, Torres R, Kanary K, Norton J , Jimerson N. Validation of the Delinum Rating Scale-Revised-98 (DRS-R-98). J Neuropsychiatry Clin Neurosci 2001; 13:229-242.

(10) Hodkinson HM. Evaluation of a mental test sc ore for a ssessment of mental impa iment in the elderly. Age and Ageing 1972; 1:233-8.

(11) American Psychiatric Association. Diagnostic and Statistical Manual of Mental Disorders. 4th Edition. Washington DC, 1994.

(12) World Medic al Assoc ia tion. Decla ration of Helsinki: Ethic al Principles for Medical Research Involving Human Subjects, 2004. http://www.wma.net/e/policy/pdf/17c.pdf. 
(13) Hart RP, Best AM, Sessler CN, Levenson J L Abbrevia ted Cognitive Test for delinum. Journal of Psychosomatic Research 1997; 43; 417-23.

(14) Wilde NJ , Strauss E, Tulsky DS. Memory Span on the Wechsler Scales. Journal of Clinical and Experimental Psychology 2004;26:539-49.

(15) Cole M, McCusker J, Dendukuri N, Han L Symptoms of delinum among elderly medic al inpatients with or without dementia. J Neuropsychiatry Clin Neurosci 2002; 14:167-175.

(16) Wahlund LA, Bjorlin GA. Delinum in clinical practice: experiences from a specialized delinum ward. Dement Geriatr Cogn Disord 1999; 10:389-392.

(17) Kakuma R, du Fort G G, Arsenault L, Perrault A, Platt RW, Monette J, Moride Y, Wolfson C. Delinum in older emergency department patients disc harged home: effect on survival. J Am Geriatr Soc 2003; 51:443-50.

(18) Meagher D, Leonard M. The active management of delinum: improving detection and treatment. Advances in Psychiatric Treatments 2008; 14: 292301.

(19) J este DV, Blazer D, Ca sey D, Meeks T, Salzman C, Schneider L, et al . ACNP White Paper. Update on use of antipsychotic drugs in elderly persons with dementia. Neuropsychopharmacology 2008; 33: 957-70. 
(20) Meagher DJ , Trzepacz PT (2007). Phenomenological distinctions needed in DSM-V: delinum, subsyndromal delinum and dementias. J Neuropsychiatry Clin Neurosci 2007 19:468-70.

(21) Mac Lullich AMJ, Beaglehole A, Ha ll RJ, Meagher DJ. Delinum and long-term cognitive impa iment. Int Rev Psychiatry 2009; 21: 30-42.

(22) Rudolph J L, Jones RN, Grande L, Milberg WP, King EG, Lipsitz LA, Levkoff SE, Marcantonio ER. Impaired executive function is associated with delinum after coronary artery bypass graft surgery. J Am Geriatr Soc 2006; 54:937-941.

(23) World Health Organization. Intemational Statistic al Classification of Disea ses and Related Health Problems, 10th Revision. Geneva, World Health Organization, 1993

(24) Franco J, Trzepacz P, Mejia M, Ochoa S. Factor analysis of the Colombian translation of the Delinum Rating Scale-Revised-98. Psychosomatics 2009; $50: 255-62$.

(25) Trzepacz PT, Mittal D, Torres R, Kanary K, Norton J, J imerson N. Delinum vs dementia symptoms: Delinum Rating Scale-Revised- 98 (DRS_R-98) and Cognitive Test for Delinum (CTD) item companisons. Psychosomatics 2002; 43:156-7 
(26) Crowder RG. Short-term memory: Where do we stand? Memory \& Cognition 1993; 21:142-145.

(27) Lichtenberger EO, Ka ufman AS, Lai ZC. Essentials of WMS-III assessment. New York, Wiley, 2002.

(28) Wilde NJ, Strauss E, Tulsky DS. Memory span on the Wechsler Scales. J Clin Exp Neuropsychology 2004; 26:539-49.

(29) Searls EF. How to Use WISC Scores. University of Florida: Intemational Reading Association, 1975.

(30) Brown L E, McGrory S, McLaren L, Sta rr J M, Deary IJ , Mac Lullich AMJ . Cognitive visual perceptual defic its in patients with delinum. J Neurol Neurosurg Psychiatry 2009;80:594-99.

(31) Collerton D, Pemy E, Mc Keith I. Why people see things that are not there: a novel perception and attention defic it model for recurrent complex visual halluc ina tions. Behav Brain Sci 2005;28:737-57.

(32) Adamis D, Momison C, Treloar A, MacDona ld AJ, Martin FC. The performance of the clock Drawing Test in elderly medical inpatients: does it have utility in the identific ation of delinum. J Ger Psychiatry Neurol 2005;18:129-133. 
(33) Cummings J The Neuropsychiatric Inventory: Assessing psychopathology in dementia patients. Neurology 1997; 48: S10-S16.

(34) Lyketsos CG, Sheppard J M, Steinberg M, Tschanz J A, Norton MC, Steffens DC, Breitner JC. Neuropsychiatric disturbance in Alzheimer's disease clusters into three groups: the Cache County study. Int J Geriatr Psychiatry 2001;16:1043-53.

(35) Meagher D, MacLullich AMJ , La urila J. Defining delinum for the Intemational Classific a tion of Disea ses, 11 th Revision. J Psychosomatic Res 2008; 65: 207-214.

(36) Folstein MF, Folstein SE, McHugh PR: Mini-Mental State: a practical method for grading the cognitive state of patients for the clinician. J Psychiatr Res 1975;12:189-198.

(37) Jorm AF. The Informant Questionnaire on cognitive decline in the elderly (IQCO DE): a review. Int Psychogeriatr 2004;16:275-93

(38) Rosen WG, Mohs RC, Davis KL. A new rating scale for Alzheimer's disea se. Am J Psychiatry 1984; 141: 1356-64. 
Table1. Demographic and medication data for the patient groups (mean \pm SD)

\begin{tabular}{|c|c|c|c|c|}
\hline & $\begin{array}{l}\text { Controls } \\
(n=40)\end{array}$ & $\begin{array}{l}\text { Delinium } \\
(n=40)\end{array}$ & $\begin{array}{l}\text { Comorbid } \\
\text { delinium-dementia } \\
(n=40)\end{array}$ & $\begin{array}{l}\text { Dementia } \\
(n=20)\end{array}$ \\
\hline Age (years)a & $66.3 \pm 10.9$ & $68.7 \pm 12.6$ & $74.9 \pm 8.5$ & $78.6 \pm 7.8$ \\
\hline Sex (\% male) & 47 & 57 & 45 & 55 \\
\hline $\begin{array}{l}\text { Number of } \\
\text { medic ations }\end{array}$ & $9.4 \pm 3.3$ & $11.0 \pm 3.7$ & $9.9 \pm 4.1$ & $9.5 \pm 3.2$ \\
\hline $\begin{array}{l}\text { Number of } \\
\text { psychotropic } \\
\text { medic ations }\end{array}$ & $2.3 \pm 1.2$ & $3.4 \pm 1.4$ & $3.2 \pm 1.7$ & $2.4 \pm 1.2$ \\
\hline
\end{tabular}

aANOVA $p<0.001$; dementia groups vs delinum and controls.

bANOVA $p=0.002$; delinum groups vs dementia and controls 
Table 2. Comparison of means \pm SD on DRS-R98 scale scores and total CTD score in fourgroups

\begin{tabular}{|l|l|l|l|l|}
\hline & $\begin{array}{l}\text { Controlsa } \\
(\mathbf{n}=40)\end{array}$ & $\begin{array}{l}\text { Delinium } \\
(\mathbf{n}=40)\end{array}$ & $\begin{array}{l}\text { Comorbid } \\
\text { delinium-dementia } \\
(\mathbf{n}=40)\end{array}$ & $\begin{array}{l}\text { Dementia } \\
(\mathbf{n}=20)\end{array}$ \\
\hline DRS-R98 Total & $4.1 \pm 1.8$ & $22.0 \pm 6.6^{\mathbf{b}}$ & $21.0 \pm 5.1^{\mathbf{b}}$ & $11.2 \pm 3.5^{\mathrm{e}}$ \\
\hline DRS-R98 Sevenity & $3.2 \pm 1.6$ & $17.9 \pm 6.1^{\mathrm{b}}$ & $16.7 \pm 4.8^{\mathrm{b}}$ & $10.2 \pm 3.5^{\mathrm{e}}$ \\
\hline $\begin{array}{l}\text { DRS-R98 } \\
\text { Noncognitive } \\
\text { subscale }\end{array}$ & $2.1 \pm 1.4$ & $9.7 \pm 5.2^{\mathrm{b}}$ & $7.4 \pm 3.3^{\mathrm{b}}$ & $3.2^{\mathrm{b}} \pm \mathrm{3}^{\mathrm{f}}$ \\
\hline $\begin{array}{l}\text { DRS-R98 Cognitive } \\
\text { subscale }\end{array}$ & $0.9 \pm 1.2$ & $8.6 \pm 3.1^{\mathrm{d}}$ & $9.5 \pm 3.2^{\mathrm{c}}$ & $7.0 \pm 3.1^{\mathrm{e}}$ \\
\hline CTD Total & $27.0 \pm 1.9$ & $13.1 \pm 7.9$ & $12.7 \pm 7.7^{\mathrm{d}}$ & $17.2 \pm 7.3^{\mathrm{e}}$ \\
\hline
\end{tabular}

a Controls sc ored in the nomal range for all measures.

b $\mathrm{p}<001$ vs dementia

c $p=007$ vs. dementia

${ }^{d} p<05$ vs dementia

e $p<001$ dementia vs. controls

${ }^{f} p<01$ dementia vs. controls 
Table 3. DRS-R98 item severities (mean scores \pm SD) for the four groups; signific ance is for comparisons using Mann-Whitney $U$ test

\begin{tabular}{|l|c|c|c|c|}
\hline DRS-R98 Item & $\begin{array}{c}\text { Controls } \\
\mathbf{( n = 4 0 )}\end{array}$ & $\begin{array}{c}\text { Delinium } \\
\mathbf{( n = 4 0 )}\end{array}$ & $\begin{array}{c}\text { Comorbid } \\
\text { delinum- } \\
\text { dementia } \\
\mathbf{( n = 4 0 )}\end{array}$ & $\begin{array}{c}\text { Dementia } \\
\text { (n=20) }\end{array}$ \\
\hline $\begin{array}{l}\text { 1. Sleep-wake cycle } \\
\text { disturbance }\end{array}$ & $0.7 \pm 0.7$ & $1.6 \pm 0.8^{\mathrm{b}}$ & $1.5 \pm 0.7^{\mathrm{b}}$ & $1.0 \pm 0.6^{\mathrm{e}}$ \\
\hline $\begin{array}{l}\text { 2. Perceptual disturbances } \\
\text { and hallucinations }\end{array}$ & $0.1 \pm 0.3$ & $0.8 \pm 1.2^{\mathrm{a}}$ & $0.7 \pm 1.0^{\mathrm{a}}$ & $0.1 \pm 0.3^{\mathrm{e}}$ \\
\hline 3. Delusions & $0.0 \pm 0.0$ & $0.2 \pm 0.7$ & $0.6 \pm 1.0^{\mathrm{a}}$ & $0.1 \pm 0.5^{\mathrm{e}}$ \\
\hline 4. Lability of affect & $0.2 \pm 0.4$ & $0.9 \pm 0.8^{\mathrm{c}}$ & $0.7 \pm 0.7^{\mathrm{b}}$ & $0.2 \pm 0.4^{\mathrm{e}}$ \\
\hline 5. Language & $0.3 \pm 0.5$ & $1.3 \pm 0.7$ & $1.0 \pm 0.8$ & $0.9 \pm 0.6$ \\
\hline $\begin{array}{l}\text { 6. Thought process } \\
\text { abnormalities }\end{array}$ & $0.4 \pm 0.5$ & $1.9 \pm 1.0^{\mathrm{cd}}$ & $1.1 \pm 0.8^{\mathrm{a}}$ & $0.6 \pm 0.9^{\mathrm{e}}$ \\
\hline 7. Motor agitation & $0.1 \pm 0.4$ & $1.6 \pm 3.4^{\mathrm{c}}$ & $0.9 \pm 0.8^{\mathrm{c}}$ & $0.2 \pm 0.4^{\mathrm{e}}$ \\
\hline 8. Motor retardation & $0.4 \pm 0.5$ & $1.3 \pm 0.8^{\mathrm{c}}$ & $0.9 \pm 1.0^{\mathrm{a}}$ & $0.4 \pm 0.5^{\mathrm{e}}$ \\
\hline 9. Orientation & $0.1 \pm 0.2$ & $1.4 \pm 0.7^{\mathrm{a}}$ & $1.4 \pm 0.7^{\mathrm{a}}$ & $0.9 \pm 0.7$ \\
\hline 10. Attention & $0.2 \pm 0.4$ & $2.2 \pm 0.9^{\mathrm{a}}$ & $2.1 \pm 0.9^{\mathrm{a}}$ & $1.6 \pm 1.1$ \\
\hline 11. Short-term memory & $0.2 \pm 0.5$ & $1.9 \pm 1.0$ & $2.0 \pm 1.0$ & $1.5 \pm 1.2$ \\
\hline 12. Long-term memory & $0.3 \pm 0.5$ & $1.3 \pm 0.9$ & $1.7 \pm 1.0$ & $1.1 \pm 1.1$ \\
\hline 13. Visuospatial ability & $0.3 \pm 0.6$ & $1.9 \pm 1.0$ & $2.3 \pm 1.9$ & $1.8 \pm 1.0$ \\
\hline $\begin{array}{l}\text { 14. Temporal onset of } \\
\text { symptoms }\end{array}$ & 0 & $1.5 \pm 0.6^{\mathrm{c}}$ & $1.6 \pm 0.7^{\mathrm{c}}$ & $0.1 \pm 0.2^{\mathrm{e}}$ \\
\hline $\begin{array}{l}\text { 15. Fluctuation in symptom } \\
\text { severity }\end{array}$ & 0 & $1.1 \pm 0.5^{\mathrm{c}}$ & $1.0 \pm 0.6^{\mathrm{c}}$ & $0.0 \pm 0.0^{\mathrm{e}}$ \\
\hline 16. Physical disorder & $1.0 \pm 0.2$ & $1.5 \pm 0.5^{\mathrm{c}}$ & $1.7 \pm 0.5^{\mathrm{c}}$ & $1.0 \pm 0.1^{\mathrm{e}}$ \\
\hline & & & & \\
\hline
\end{tabular}

a More impaired than dementia at $p \leq 05$

b More impaired than dementia at $p \leq .01$

c More impaired than dementia at $p \leq 001$

d More impaired than delinum-dementia at $p \leq 001$

e No difference between dementia and controls 
Table 4. CTD item scores for the four groups using Mann Whitney $U$ test Controls perfomed in the nomal range for eac $h$ item.

\begin{tabular}{|c|c|c|c|c|}
\hline CTD Item & $\begin{array}{l}\text { Controls } \\
(n=40)\end{array}$ & $\begin{array}{l}\text { Delinium } \\
(n=40)\end{array}$ & $\begin{array}{l}\text { Comorbid } \\
\text { delinium-dementia } \\
(n=40)\end{array}$ & $\begin{array}{l}\text { Dementia } \\
(n=20) c\end{array}$ \\
\hline Orientation & $6.0 \pm 0.0$ & $4.5 \pm 1.0$ & $3.0 \pm 2.3$ & $4.3 \pm 2.2$ \\
\hline Attentiona & $4.5 \pm 1.0$ & $1.5 \pm 1.6$ & $1.7 \pm 1.8$ & $2.7 \pm 1.6$ \\
\hline Memory & $5.3 \pm 0.8$ & $2.9 \pm 2.3$ & $2.3 \pm 2.0$ & $3.3 \pm 2.0$ \\
\hline Comprehension & $5.6 \pm 0.5$ & $4.1 \pm 1.6$ & $3.9 \pm 1.6$ & $4.2 \pm 1.6$ \\
\hline Vigilance $^{b}$ & $5.5 \pm 1.0$ & $1.4 \pm 1.8$ & $1.8 \pm 2.2$ & $2.6 \pm 1.9$ \\
\hline
\end{tabular}

a Delinum and delinum-dementia $<$ dementia at $p<0.05$

b Delinum <dementia at $\mathrm{p}<0.05$

c Dementia $<$ controls on all items at $p<0.001$ 
Figure 1. Boxplots of distribution of Total DRS-R98 scores for diagnostic groups

Figure 2. Boxplots of distribution of scores on the CTD spatial span item forwards (SSF) and backwards (SSB) for diagnostic groups. 


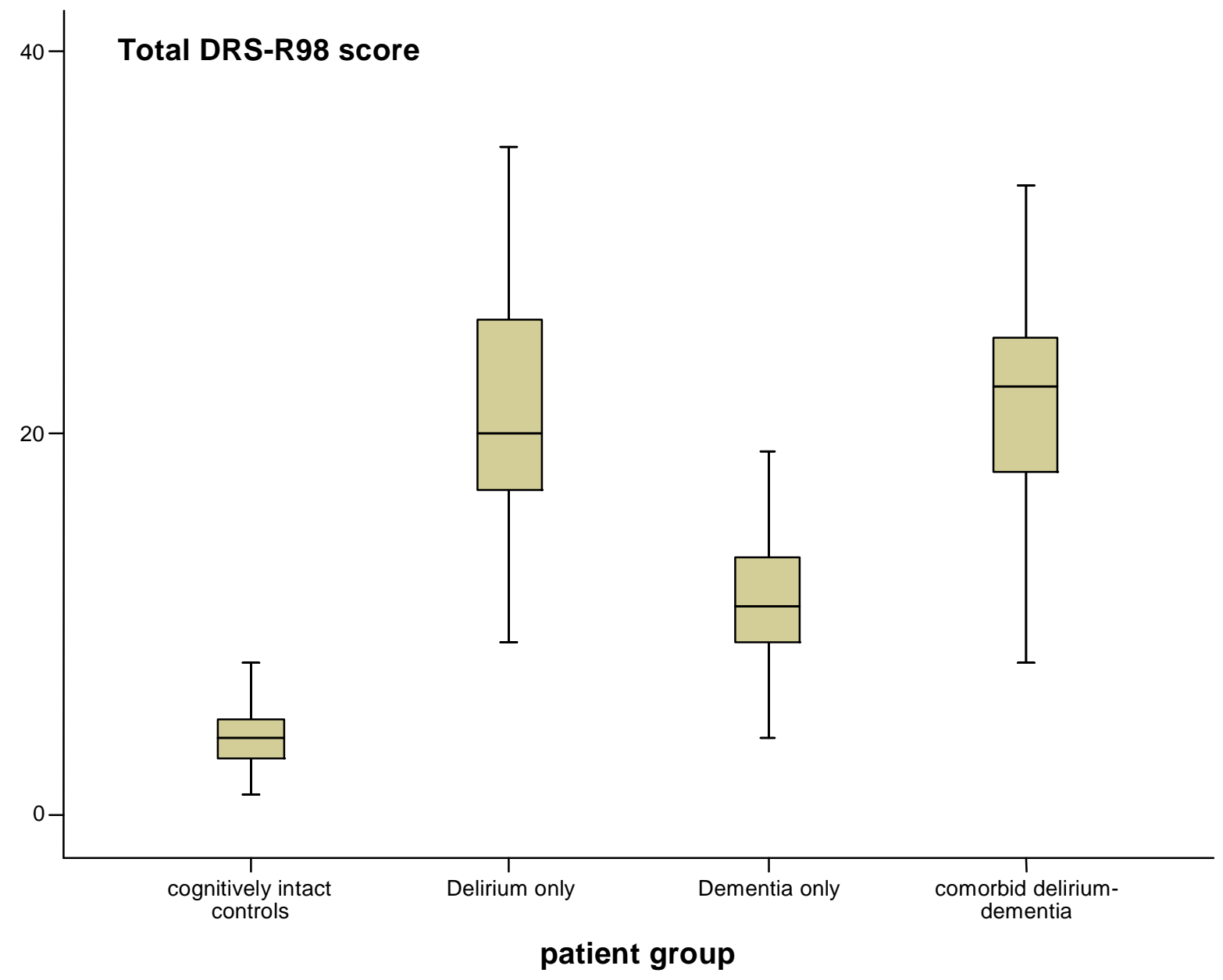




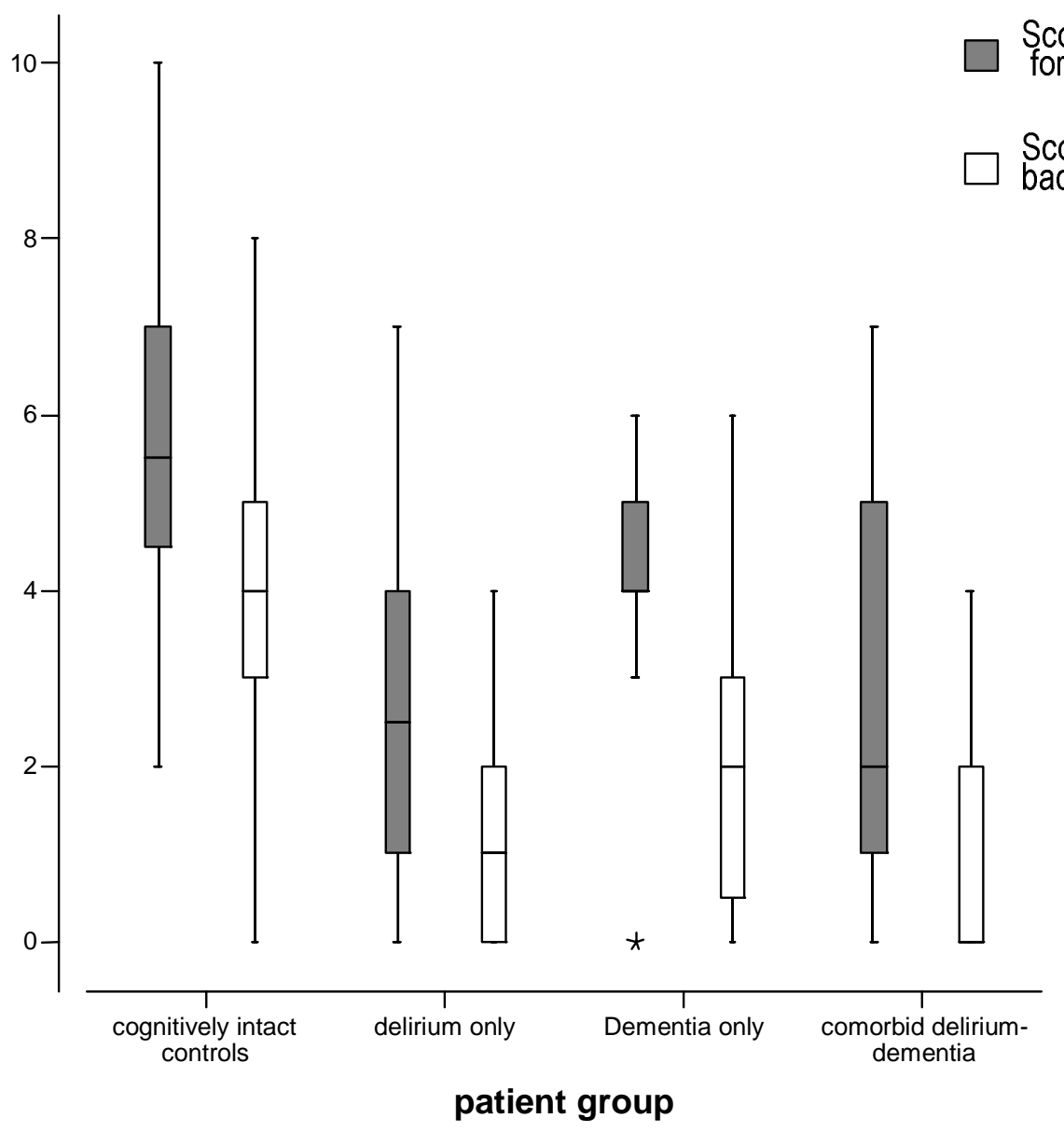

Score on Spatial spatial span orwards from CTD

core on Spatial spatial span

backwards from CTD 